\title{
La economía creativa como fuente de desarrollo cultural y económico
}

Creative Economy as a Source of Cultural and Economic Development

\section{Tania GARCía LORENZo}

Escritora investigadora

La Cultura y el Desarrollo es un tema recurrente en las agendas internacionales, y siempre será motivo para un intercambio constante y de múltiples aristas, que no se agota, debido a que ambos conceptos no tienen los mismos significados para todas las sociedades. Sin embargo, han existido avances indiscutibles en los últimos decenios, porque las culturas han sido identificadas como dimensión y complemento de los factores que generan y difunden el desarrollo, para ser finalmente asumida como su esencia misma.

Esto quedó demostrado cuando, desde fines del siglo pasado, la Declaración Universal sobre la Diversidad Cultural de la Unesco reflejó el consenso internacional alcanzado de que «la cultura debe ser considerada como el conjunto de los rasgos distintivos espirituales y materiales, intelectuales y afectivos que caracterizan a una sociedad o a un grupo social y que abarca, además de las artes y las letras, los modos de vida, las maneras de vivir juntos, los sistemas de valores, las tradiciones y las creencias». 
Vista la cultura en su acepción más laxa, abarca todo el sistema de valores, cosmovisiones, conocimientos y herencias que conforman la identidad de una sociedad incluidas las artes y las letras que las expresan. La endogeneidad, la creatividad y la diversidad, son valores que emanan de las culturas. Y, de la misma forma, todo el desarrollo que se alcance por las sociedades, influye, de manera decisiva, en el arte que emerge desde cada espacio territorial y en el proceso de creación-consumo, en el que se materializan y realizan las expresiones culturales.

La cultura en general y las artes en particular, son expresión y parte esencial de la vida cotidiana de los seres humanos, aunque el consumo artístico y literario no sigue las mismas pautas de comportamiento de los restantes consumos convencionales. Las experiencias estéticas y las preferencias por el arte demuestran características de consumo diferentes. Son esencialmente obras del espíritu, que generan satisfactores incomparables. De la misma forma, desde la economía, cada vez es más reconocido que estos bienes y servicios difieren significativamente de otros productos, tanto por las características de sus procesos productivos como por las particularidades de su demanda, que los tipifica como un mercado peculiar.

Este ha sido uno de los rasgos más relevantes del devenir de las sociedades y, ha estado presente en la expansión creciente de aquellas producciones que tienen el pensamiento, la inteligencia y la innovación, como núcleo fundamental donde se reconoce que el desarrollo de las facultades creativas se ha convertido en el factor esencial para la eficiencia de las industrias.

La llamada por algunos expertos nueva economía, basada en el talento humano y la creatividad ha emergido como poderosos motores del desarrollo contemporáneo. Este concepto fue suscrito por la Conferencia de las Naciones Unidas para el Comercio y el Desarrollo (UNCTAD) cuando definió la economía 
creativa como «el conjunto de actividades económicas que se basan en el conocimiento y que comprenden aspectos culturales, sociales y económicos, en interacción con la tecnología, la propiedad intelectual y los objetivos turísticos» ${ }^{1}$.

Todo ello ha provocado que sean invertidos recursos crecientes en la producción basadas en la innovación, incluidos los bienes y servicios culturales y se hayan posicionado a tenor con los modelos económicos dominantes en cada región y país. De la misma forma, la desigual distribución de las capacidades económicas, los distintos intereses y las diferentes interpretaciones alrededor del papel de la creatividad y en especial de la cultura y el arte en las sociedades, ha determinado importantes diferencias de enfoques e interpretaciones.

La relación entre la economía y la cultura resulta imprescindible abordarla, ante todo por su condición de sostén del desarrollo cultural y, derivado de ello, por la capacidad de potenciar sus recursos para el desarrollo económico. Es una doble condición en permanente tensión. Las exigencias a la producción cultural, como generador de desarrollo económico, no debe someter el importante papel que ha jugado la cultura en el desarrollo de la humanidad, como forjadora de identidad y de su mayor cualidad, que son los fundamentos civilizatorios de la sociedad.

La Resolución 74/198 aprobada el 19 de diciembre del 2019, por la Asamblea General de Naciones Unidas, declaro al 2021 como el Año Internacional de la Economía Creativa para el Desarrollo Sostenible porque es la creatividad la que ofrece el contexto, los valores, la subjetividad, las actitudes y las aptitudes en las cuales han de tener lugar los procesos económicos.

1 UNCTAD (2008). Informe sobre la Economía Creativa 2008. Disponible en: http://unctad.org/es/ docs/ditc20082ceroverview_sp.pdf. Citado por La Economia Creativa, cuadernos informativos Plan Maestro. 
A quince años de que se acuñara el término economía creativa, el concepto es aún muy debatido, y se considera uno de los más difundidos y novedosos en el pensamiento económico mundial contemporáneo. La mirada desde el capital jerarquiza las potencialidades de determinados sectores altamente rentables, entre los que están los bienes y servicios culturales. Lo considera una nueva y atractiva oferta mercantil con características particulares, con demanda extensiva y solvente y oportunidades de crecimiento sostenido.

Así se manifiesta cuando se señala: «Desde los primeros estudios sobre el impacto económico de las industrias culturales y creativas en los años 80 , se demostró con claridad que estas industrias crecen más rápido que la economía en su conjunto. Muchas de ellas incluso crecen a tasas de dos dígitos. Más aún: son intensivas en generación de empleo, en especial para jóvenes. Este sector de la economía demostró además ser más resiliente a las crisis económicas, como quedó claro tras la crisis del 2008, ya que esas industrias sufrieron menos y se recuperaron más rápido, colaborando con la reactivación económica de los países»².

El enfoque de la economía creativa, desde el desarrollo económico y social para todas las sociedades, la identifica como dinamizadora de las economías tradicionales. Su producción no es un producto transable más en el mercado. En una visión más holística del término, el consumo de bienes y servicios creativos, contribuye a elevar la calidad de vida de quienes lo consumen al disponer de capacidad adquisitiva para ello o como parte del consumo social público.

Pensar el desarrollo económico integral de la sociedad, de forma creativa implica transformar la noción espuria de competitividad que se ha instituido a partir de la mayor explotación

2 Luis Alberto Moreno (presidente BID). Revista Economía Colombiana, n. ${ }^{\circ}$ 354, pp. 10-17. Especial Economía Naranja. Contraloría General de la República. 
de la fuerza laboral, y evolucionar hacia una noción de efectividad y eficiencia a través de la elevación de la capacidad colectiva basada en la innovación y la cooperación, como cualidades y propósitos que se pueden y deben expresar en todas las ramas del quehacer humano.

No es lo mismo un territorio donde la identidad colectiva se convierten en sinergias para la elevación de la calidad de la vida, que aquel donde la pobreza ha pasado a ser parte de su resignación y conformidad. No se trata de buscar una economía creativa, que jerarquice la innovación y la creatividad, solo o principalmente, para la obtención de mayores tasas de rentabilidad y cuotas de apropiación de capital. Estas nuevas corrientes de pensamiento marcarán la diferencia, si se trata de una proyección comprometida con el desarrollo cultural y económico para beneficio de todas las sociedades. Serán verdaderamente creativas, las políticas públicas que asumen la responsabilidad social de transformar cada territorio y proyectar los países hacia nuevos derroteros.

En ese largo camino la Unesco y la Comisión Europea han mostrado la necesidad y posibilidad de vincular las dimensiones económicas y culturales de forma armónica.

Para Audrey Azoulay, directora general de la Unesco ${ }^{3}$, «Las industrias culturales y creativas son uno de los sectores en más rápida expansión de la economía global; podrían mejorar la vida de la ciudadanía y hacer frente a varios de los Objetivos de Desarrollo Sostenible de la ONU». También en documentos rectores, la Unesco define entre las Principales características de las industrias culturales y creativas, la Intersección entre la economía, la cultura y el derecho; y señala con particular fuerza la doble naturaleza: económica (generación de riqueza y empleo) y cul-

3 Manifiesto Cultura para el Desarrollo. Foro Cultura para el Futuro. Una iniciativa de la Comisión Europea. Bruselas, 16-17 de junio de 2019, p. 12. 
tural (generación de valores, sentido e identidades) ${ }^{4}$. La Unesco promueve la cultura fortaleciéndola desde la economía, integra la promoción del proceso creativo y el fortalecimiento del contexto cultural de las naciones, con el fomento de la industria y esa es la manera más efectiva de proteger el patrimonio nacional e impulsar la cohesión social.

De la misma forma, Stefano Manservisi ${ }^{5}$ ha señalado que: «La cultura es esencial para la cohesión social. Mediante la cultura, podemos luchar contra la desigualdad. La cultura proviene del pueblo y pertenece al pueblo».

Esa relevante presencia de los bienes creativos en los mercados exportadores mundiales ha tenido un comportamiento volátil en los últimos años. Según estadísticas del Centro de Comercio Internacional (ITC por sus siglas en ingles), en 2018, los ingresos generados por esos fondos exportables excedieron los 553 mil millones de dólares, marcando un punto de inflexión a la tendencia decreciente acumulada desde 2014 hasta 2017. La propia fuente muestra una significativa y creciente concentración de esas exportaciones en un grupo cada vez más reducido de países y mercados.

En 2018, la estructura geográfica de los proveedores demuestra que, diez países concentraron el 70\% de las exportaciones de bienes creativos ${ }^{6}$. Estos fueron: China; Estados Unidos de América; Italia; Francia; Alemania; India; Reino Unido; Hong Kong; Emiratos Árabes Unidos y Suiza. La escasa presencia de los países subdesarrollados resulta abrumadora, cuando emergen de sus raí-

\footnotetext{
4 Políticas para la Creatividad. Guia para el desarrollo de las Industrias culturales y creativas. Unesco. Sector de la Cultura 2010. Sobre definiciones: ¿Qué se entiende por industrias culturales y creativas?

5 Director General de Cooperación Internacional y Desarrollo de la Comisión Europea. Coloquio Internacional Cultura para el Futuro, Bruselas 16-17 de junio 2019.

6 Cálculos de la autora a partir de cálculos del ITC basados en estadísticas de UN COMTRADE y de ITC.
} 
ces importantes movimientos culturales. Por otra parte, la estructura por productos de los fondos exportables presenta también una alta concentración. El 55\% de las exportaciones conciernen a 14 productos y el 20\% a artículos de joyería ${ }^{7}$. Como es conocido, las joyas son, junto a Pinturas y bienes raíces, tres «cielos seguros» en el mercado monetario internacional, lo que induce a pensar que, en la práctica, muchas de estas transacciones con obras de arte cumplen funciones financieras más que culturales.

La alta concentración del mercado de bienes, tanto geográfica como por productos no se corresponde con la riqueza cultural acumulada de las sociedades, lo que está identificando distorsiones e insuficiencias estructurales que demandarían análisis y acciones internacionales intencionadas, para que los beneficios económicos que se derivan de este mercado, tengan mayor alcance para la comunidad internacional.

Está documentado por diversas vías, que las industrias culturales y creativas tienen presencia y comportamiento ascendente en el continente latinoamericano y caribeño y en el mundo. Tres organismos multilaterales mundiales han avanzado significativamente en el desarrollo de sistemas de información que contribuyen a evidenciar la presencia de las industrias culturales y creativas en el devenir económico mundial. La Unesco, la UNCTAD y la OMPI. También la OEI, aborda de forma prioritaria los temas de la economía del arte y la cultura. En el ámbito regional el BID, la CEPAL, y el SELA entre otras, han producido avances en el abordaje al tema. A escala de los países, además de lo registrado en sus sistemas de cuentas nacionales, se impulsó con fuerza desde el Convenio Andrés Bello y otras instituciones culturales, la creación de las Cuentas Satélites, que mucho han contribuido al conocimiento de las estadísticas culturales y económicas de la cultura de los países que la han puesto en valor.

7 COMTRADE (código 711311).

García Lorenzo, Tania (2021). «La economía creativa como fuente de desarrollo cultural y económico». Monograma. Revista Iberoamericana de Cultura y Pensamiento, n. ${ }^{\circ}$ 9, pp. 379-391. doi: 10.36008/monograma.2021.09.2305. http: revistamonograma.com. ISSN: 2603-5839. 
Sin embargo, no se ha avanzado hacia un marco conceptual universalmente consensuado y reconocido para determinar, en mayor magnitud, la relevancia cultural y económica, así como las características particulares de este campo de actuación.

Reconociendo el gran avance alcanzado en esta dirección, en tanto todas las perspectivas ofrecidas son sumamente necesarias y útiles, aún permanecen muchas dificultades para acceder a las estadísticas indispensables para producir los análisis culturales y económicos, globales y por países, que son necesarios para respaldar las propuestas y cursos de acción, que se pueden impulsar, para fortalecer las industrias culturales y creativas y de esa forma proteger el patrimonio cultural de los países, regional y mundial, teniendo en cuenta las particularidades de estas producciones y la velocidad de las mutaciones que tienen lugar en los procesos de creación-consumo.

Se han producido profundas transformaciones en los procesos creativos, en los soportes en que se expresan, los medios y vías para la promoción; los canales de distribución y también las vías y medios para la recepción de los mensajes, de cada manifestación artística. Hoy se aprecia una disparidad creciente en los accesos al consumo cultural. «Si bien es evidente que en la actualidad no podemos pensar estos consumos sin tener en cuenta las mediaciones tecnológicas de la vida cotidiana, $[. .$.$] en$ América Latina estos procesos se dan en el marco de progresivas condiciones de desigualdad desde la perspectiva cuantitativa del acceso al consumo de medios por parte del ciudadano».

Los servicios son un importante componente de la economía creativa en los cuatro modos de suministros refrendados en el Artículo primero del Acuerdo General de Comercio de Servicios. Se han ido convirtiendo en una de las mayores áreas

8 Mutaciones del Consumo Cultural en el Siglo XXI. Tecnología, espacios y experiencias. ALAS, CLACSO, Editorial Teseo, 2019, p. 26. 
de crecimiento del sector. Su expansión antecede pero se ha fortalecido con el acelerado desarrollo de la tecnología de la información y las comunicaciones, así como por la mayor presencia del comercio digital en las economías domésticas y el mercado internacional. Si bien, la renovación tecnológica implica una inversión altamente costosa, estas innovaciones han demostrado tener una mayor capacidad de recuperación frente a las crisis económicas, una mayor capacidad de expansión en el plano internacional y mayores tasas de rendimiento por peso de inversión.

Sin embargo, es de alta complejidad la recopilación de la información, su medición y estimación. Los países en desarrollo no disponen de la información necesaria sobre el comercio de servicios. No obstante, que no se disponga de la información no significa que no exista y menos que no tengan una presencia destacada en su cartera de negocios. En la dirección de consolidar una metodología para el registro, análisis y proyección de este sector, se dan pasos por parte de UNCTAD y la Unesco.

Según el informe de la UNCTAD Creative Economy Outlook, Trends in creative industries, 2002-2015', 20 son los ítems que se incluyen en el sector de servicios creativos. En el año 2018 las exportaciones globales de servicios representaron el 23\% del comercio total mundial de bienes y servicios y ascendieron a USD $\$ 5,8$ billones con un crecimiento sobre 2017 de 7,7\%, mientras que América Latina y el Caribe solo alcanzó el modesto crecimiento de $1,7 \%{ }^{10}$. Esta situación demanda una acción de los actores del área, en tanto se está produciendo una transformación de las industrias creativas que impactará severamente a las economías subdesarrolladas, si no se producen las innovaciones necesarias.

9 Publicado en 2018.

10 Internacional Trade in service, 2018. UNCTAD/GDS/DSI/MISC/2019/9. UNCTADSTAT.

García Lorenzo, Tania (2021). «La economía creativa como fuente de desarrollo cultural y económico». Monograma. Revista Iberoamericana de Cultura y Pensamiento, n. ${ }^{\circ}$ 9, pp. 379-391. doi: 10.36008/monograma.2021.09.2305. http: revistamonograma.com. ISSN: 2603-5839. 
La digitalización está transformando los mercados culturales. Son conocidos los análisis y estudios especializados que evidencian los cambios que tienen lugar en la estructura de los ingresos. Ello significa que aquellos productores que no disponen de los medios tecnológicos requeridos para generar productos culturales para el ámbito digital están en posición desventajosa. Si no se dispone de plataformas de distribución amplias y diversas, se mantendrá la dependencia y subordinación a los grandes grupos productores y distribuidores corporativos. Esas desigualdades se producen con mayor profundidad en los territorios más alejados de los centros de poder y acceso a las nuevas tecnologías comunicacionales.

Todo ello implica asumir los cambios, que han tenido lugar antes y con la COVID para asegurar que los mensajes de la creación artística y literaria llegue a todos los espacios de la sociedad. Un axioma de las finanzas dice que dejar de ganar es perder, por lo que el costo de no desarrollar la industria cultural a escala de cada país es la perdida de los ingresos que esa industria está en condiciones de generar, cuando se dispone del contenido principal, que es el amplio y reconocido movimiento artístico y literario. Pero la verdadera y más importante pérdida, del no desarrollo de la economía creativa de los países subdesarrollado es la pérdida del patrimonio cultural de nuestras naciones.

El mercado de la música es uno de los que más se ha transformado, además de un brusco cambio en sus ingresos totales esa transformación está generando cambios en la estructura del consumo. En efecto, el dominio pleno del mercado por el disco en físico, ha cedido su lugar, en la actualidad, a una fuerte presencia de las escuchas y las descargas digital. Con menos presencia se mantienen los ingresos por derechos de presentación en vivo y por sincronización. 


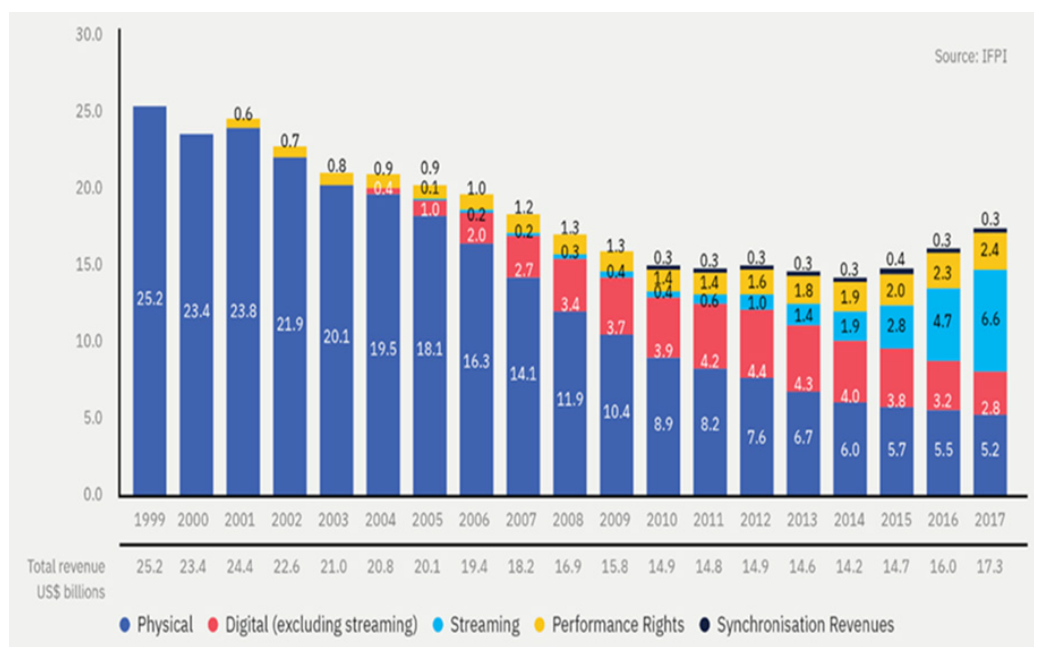

FIGURA 1. Ingresos globales de la industria de la música grabada 1999-2017 (en billones de dólares).

Los diez mercados más importantes del consumo de la música son EUA; Japón; RU; Alemania; Francia; Corea del Sur; China; Canadá; Australia; Brasil. Y el 56,1\% de ese consumo es por escuchas a través de los soportes de consumo digital ${ }^{11}$. Esa transformación ha implicado cambios radicales en las formas de crear, producir, promover, distribuir y consumir la música, además de transformar los soportes para el consumo. No hay suficientes análisis sobre cuál es el impacto que todas esas transformaciones ha tenido en las creaciones musicales autóctonas de nuestras naciones. $\mathrm{Y}$ estos vacíos se agudizan en el ciberespacio, donde se pone a prueba permanentemente, la inteligencia y la espiritualidad.

En estos procesos de cambios y desigualdades crecientes, la cooperación cultural se constituye en una de las bases fundamentales sobre las que se asientan las estrategias de desarrollo lo

11 IFPI. Global Music Report. The industry in 2019, p. 7.

García Lorenzo, Tania (2021). «La economía creativa como fuente de desarrollo cultural y económico». Monograma. Revista Iberoamericana de Cultura y Pensamiento, n. ${ }^{\circ}$ 9, pp. 379-391. doi: 10.36008/monograma.2021.09.2305. http: revistamonograma.com. ISSN: 2603-5839. 
que resulta lógico al estar en correspondencia con la naturaleza de la gestión cultural y la construcción de los diálogos interculturales. La cooperación, el dialogo y la concertación son los mecanismos más efectivos para la articulación interinstitucional en pro de la promoción de políticas culturales inclusivas e innovadoras y la vinculación concreta y efectiva de todos los actores que participan en estos propósitos.

La XXVII Cumbre Iberoamericana de jefes de estado y de gobierno: Innovación para el Desarrollo Sostenible-Objetivo 2030, efectuada el pasado 21 de abril de $2021^{12}$, abordó de forma extensa los principales desafíos que se enfrentan en la actualidad, incluida la cooperación iberoamericana y en ese contexto señaló en el párrafo 15 de su declaración final «Consideraron que los organismos multilaterales de financiamiento para el desarrollo deben ser fortalecidos para lograr un mayor impacto ante las crisis multidimensionales, y contribuir de forma decidida, transparente y eficiente al desarrollo sostenible, a través del acceso justo e inclusivo a mecanismos innovadores y efectivos de financiación y otras modalidades de cooperación, que estén ligados a estrategias de transformación tecnológica y productiva y de desarrollo social, así como a políticas medioambientales de medio y largo plazo».

Existen experiencias de cooperación internacional de organismos multilaterales y ONG que constituyen ejemplos de «buenas prácticas» encaminadas a impulsar proyectos que pueden aportar soluciones relevantes y complementar esfuerzos nacionales, para enfrentar los grandes dilemas que se confrontan en la actualidad. Los problemas de la obsolescencia tecnológica, promover centros de entrenamientos para la actualización e intercambios de conocimientos, así como la generación de empren-

12 Secretaría Iberoamericana, Declaración De Andorra Innovación para el Desarrollo Sostenible-Objetivo 2030. Iberoamérica frente al reto del Coronavirus. Texto de la Presidencia. 
dimientos que contribuyan al fortalecimiento de las corrientes productivas de los países debieran estar en las prioridades de ese movimiento de cooperación cultural que ya se aprecia.

El Proyecto ONUDI, MINCULT, KOICA ${ }^{13}$ para el desarrollo de la industria musical cubana es un buen ejemplo de cooperación para el desarrollo cultural y económico. Según informaciones diversas, Transcultura, proyecto impulsado por la Comisión Europea y la Unesco tiene como objetivo profundizar la integración de la región del Caribe, fortalecer la cooperación y los intercambios pueblo a pueblo, tanto al interior de la región como entre esta y la Unión Europea, tomando como eje articulador el desarrollo cultural. Son proyectos que pueden obtener resultados medibles, que demuestren la validez de los propósitos y efectividad de los fondos utilizados.

Son nuevos escenarios que hay que observar, estudiar, validar y fortalecer para acompañar de forma pro activa, desde la creación artística y literaria y el movimiento cultural, la formulación de estrategias de desarrollo cultural y económico.

La producción cultural es una fuerza productiva directa en el mundo, en el hemisferio y en Cuba. Sin embargo, puede disponerse del caudal y no del cauce que lo movilice y potencie. Múltiples son los desafíos del presente que pueden encontrar soluciones con las acciones conjuntas de todos los actores de las sociedades.

13 ONUDI MINCULT KOICA. Contribución de la Industria de la Música al desarrollo inclusivo y sostenible: el caso CUBA «la Isla de la Música». 